\title{
Association Between Dispensing Channel and Medication Adherence Among Medicare Beneficiaries Taking Medications to Treat Diabetes, High Blood Pressure, or High Blood Cholesterol
}

Reethi N. Iyengar, PhD, MBA, MHM; Dhanur S. Balagere, MS; Rochelle R. Henderson, PhD, MPA; Abbey L. LeFrancois, PharmD; Rebecca M. Rabbitt, MS, PharmD; and Sharon Glave Frazee, PhD, MPH

\begin{abstract}
BACKGROUND: Medication adherence, defined as taking medications as prescribed, is a key component in controlling disease progression and managing chronic illnesses such as diabetes, hypertension, and high blood cholesterol. These diseases constitute 3 of the top 5 most prevalent conditions among Medicare beneficiaries, warranting further attention to find ways to promote better medication adherence. The scientific literature has established the clinical and financial benefits of medication adherence and the role of dispensing channel in impacting adherence to medications. However, a common limitation in channel-adherence studies is the failure to control for healthy adherer effect (HAE), referring to individuals who are likely to engage proactively in activities that improve their adherence. Healthier individuals may choose the home-delivery channel to ensure continuity in their medication regimens and to minimize obstacles to adherence, such as inadequate access, inconvenience, and financial concerns. Thus, better medication adherence in home delivery may reflect healthier patients' predisposition to self-select for home delivery options. To accurately attribute the impact of dispensing channel on adherence, research would need to control for bias from a patient's predisposition to be adherent.
\end{abstract}

OBJECTIVE: To examine the association of pharmacy dispensing channel (home delivery or retail pharmacy) with medication adherence for Medicare Part $D$ beneficiaries taking medications for diabetes, hypertension, or high blood cholesterol, while controlling for low-income subsidy status, differences in days supply, and prior adherence behavior (PAB) as a way to partly control for HAE.

METHODS: A retrospective analysis using de-identified pharmacy claims data from a large national pharmacy benefits manager between 0ctober 2010 and December 2012. Continuously eligible Medicare Part $D$ beneficiaries (Medicare Advantage and prescription drug plans participants only) aged 65 years or older who had an antidiabetic, antihypertensive, or antihyperlipidemic prescription claim between 0ctober and December 2010, were identified and followed for the next 2 years. Those enrolled in a home delivery auto refill program were excluded from this analysis. Multivariate logistic regression was used to evaluate the impact of dispensing channel on medication adherence, controlling for differences in demographics, low-income subsidy status, disease burden, and drug-use pattern. Patients with a proportion of days covered of $\geq 80 \%$ were considered to be adherent. The analysis controlled for PAB by using patients' adherence status in the year 2011.

RESULTS: The final analytical samples consisted of 150,389 diabetic patients, 615,618 hypertension patients, and 358,795 high blood cholesterol patients. The adjusted odds of being adherent for beneficiaries using home delivery were 1.25 times higher $(\mathrm{Cl}=1.20-1.30)$ for diabetes medications, 1.29 times higher $(\mathrm{Cl}=1.27-1.32)$ for hypertension medications, and 1.26 times higher $(\mathrm{Cl}=1.23-1.29)$ for high blood cholesterol medications, compared with beneficiaries using retail channels to obtain their prescriptions. PAB was the strongest contributor to the odds of a patient being adherent across all 3 therapy classes, ranging from odds ratio of 4.48 to 8.09 .

CONCLUSIONS: After excluding patients who received any prescriptions via home delivery auto refill programs and controlling for $\mathrm{PAB}$, differences in days supply, low-income subsidy status, demographics, and disease burden, Medicare beneficiaries who use home delivery for antidiabetics, antihypertensives, or antihyperlipidemics have a greater likelihood of being adherent than patients who fill their prescriptions at retail. The results of this study provide evidence that where medications are received may impact adherence, even when controlling for PAB. Use of the home delivery dispensing channel may be an effective method to improve adherence for Medicare beneficiaries.

J Manag Care Pharm. 2014;20(8):851-61

Copyright $\odot 2014$, Academy of Managed Care Pharmacy. All rights reserved.

\section{What is already known about this subject}

Diabetes, hypertension, and high blood cholesterol are 3 of the top 5 most prevalent chronic conditions among Medicare beneficiaries. Pharmacotherapy is a key factor in improving disease management and controlling disease progression.

Dispensing channel could impact adherence to medications. Increased adherence observed in Medicare patients using home delivery is speculated to be merely an artifact of home delivery auto refill programs, healthier patients choosing home delivery, increased days supply of medications, and lower proportion of patients on low-income subsidy.

\section{What this study adds}

Among Medicare beneficiaries, home delivery channel is associated with improved adherence rates across all 3 therapy classes, compared with retail, and is not just an artifact of auto refill programs, healthy adherer effect, lower proportion of patients on low-income subsidy, and increased days supply.

Comparing (multivariate adjusted) patients receiving 90-day supply of medications through home delivery to patients receiving 90-day supply through retail also indicated that adherence rates were significantly higher in home delivery users. 


\section{What this study adds (continued)}

This study provides evidence to the Centers for Medicare \& Medicaid Services, health plan sponsors, and managed care organizations, encouraging use of more effective dispensing channels and presents home delivery as a viable complementary strategy to address medication nonadherence.

$\mathrm{H}$ ypertension, high cholesterol, and diabetes are major public health problems in the United States and are expected to worsen with the aging of the population. These conditions also constitute major risk factors for serious cardiovascular and cerebrovascular conditions and events, such as coronary heart disease, myocardial infarction, congestive heart failure, and stroke. Among Medicare beneficiaries, these conditions are 3 of the top 5 most prevalent chronic conditions. According to the Centers for Medicare \& Medicaid Services (CMS), in 2010, 58\% of Medicare beneficiaries had hypertension; $45 \%$ had high cholesterol; and 28\% had diabetes. ${ }^{1}$ Although there is no known cure for these diseases, pharmacotherapy is a key factor in controlling disease advancement and improving disease management. ${ }^{2,3}$ However, in order to fully benefit from the medications, patients must take medications as prescribed.

Previous studies have concluded that nonadherence to medication is associated with increased emergency department visits, increased hospitalization, increased disease morbidity, reduced treatment effectiveness, and decreased survival likelihood..$^{4-9}$ Apart from adverse clinical outcomes, medication nonadherence is also recognized as a significant contributor to waste, inefficiency, and financial drain on the health care system. ${ }^{10}$ Research on the economic impact of Medicare Part $\mathrm{D}$ indicates that better adherence to medication is linked to annual medical savings for beneficiaries. ${ }^{11}$ Overall, research shows that poor medication adherence results in additional Medicare costs of $\$ 49-\$ 840$ per beneficiary per month. ${ }^{12}$

Although reasons for nonadherence vary, Medicare beneficiaries forget to take their medications, procrastinate on refills or renewals of prescriptions, or possibly have transportation or caregiver time dependencies. Additionally, financial concerns may impede adherence. ${ }^{13}$ Literature suggests that Medicare patients exhausting their prescription benefits during the "coverage gap" are required to pay more and thus may reduce the number of prescriptions they have filled. ${ }^{14,15}$ Programs under health care reform, such as the coverage gap discount program, which offers discounts on brand and generic medications when beneficiaries are in the gap, may reduce the cost barrier for beneficiaries filling medications. ${ }^{16}$

Improving adherence to medications can have a direct financial impact on Medicare health plans. CMS established the Five-Star Quality Rating System in 2007 to encourage
Medicare Advantage Prescription Drug (MAPD) and prescription drug plans (PDP) to improve quality and safety. ${ }^{17}$ With health care reform, Medicare is authorized to pay financial bonuses to plans that achieve 4 stars or higher. Recognizing the high prevalence of diabetes, hypertension, and high blood cholesterol among Medicare beneficiaries and the importance of medication adherence, CMS has included 3 adherence measures, 1 each for diabetes, hypertension, and high blood cholesterol, as part of the Five-Star rating program and has categorized the measures in one of the highest weighted categories of intermediate outcome-based measures.

Previous studies have indicated that obtaining medication through home delivery is an alternative for improving medication adherence. ${ }^{18-20}$ The home delivery dispensing channel has been promoted as more cost-effective and convenient than retail pharmacies..$^{21,22} \mathrm{~A}$ recent study also indicated that home delivery was associated with fewer preventable emergency department visits in patients aged 65 years or older. ${ }^{23}$ In contrast, retail pharmacies claim to add value in terms of pharmacist face-to-face interaction..$^{24-26}$ Home delivery proponents contend that medication adherence is greater among patients who secure medications via home delivery. ${ }^{27}$ Critics of home delivery attribute improved adherence to increased days supply per prescription or auto refill programs (automatically dispensing remaining fills to patients) that are typically in place for home delivery pharmacies. ${ }^{25}$ Retail proponents argue that auto refill programs may result in higher adherence in home delivery but may also lead to higher waste compared with retail. To our knowledge, there is little evidence that suggests that adherence in home delivery is better than retail, after excluding the benefits of home delivery auto refill programs.

Most adherence studies fail to control for underlying factors that confound the relationship between adherence and selection of dispensing channel. One of these confounders is healthy adherer effect (HAE), a beneficiary's predisposition to engage in healthy alternatives, aside from the impact of home delivery auto refill program and days supply differential between home delivery and retail. ${ }^{28,29}$ Previous studies examining medication adherence among Medicare beneficiaries have either (a) not examined the relationship between dispensing channel and adherence, ${ }^{30}(\mathrm{~b})$ not controlled for prior adherence behavior (PAB), ${ }^{6,25}$ or (c) not addressed differences in days supply between home delivery and retail. ${ }^{18}$

To our knowledge, this study is the first to examine the association of dispensing channel with medication adherence among Medicare beneficiaries that also controls for PAB effect and excludes patients who were engaged in home delivery auto refill programs. The objectives for this study were to address the aforementioned biases and limitations, in addition to controlling for other known confounders, and to examine the effect of dispensing channel on adherence for medications to treat diabetes, hypertension, and high blood cholesterol among Medicare 
beneficiaries. This study hypothesized that the home delivery channel is associated with better adherence rates among Medicare beneficiaries compared with the retail channel.

\section{Methods}

\section{Study Population}

This study used prescription claims data from a sample of Medicare Part D beneficiaries whose pharmacy benefits were managed by a large national pharmacy benefit management company. Inclusion was limited to patients who (a) were continuously enrolled with pharmacy benefits from October 1, 2010, until December 31, 2012, (b) were aged 65 years or older, and (c) had any prescription claim for antidiabetics, antihypertensives, or antihyperlipidemics during the index period (October 1 to December 31, 2010). Patients who were engaged in a home delivery auto refill program during the analysis period (described below in Research Design), or who did not have a prescription fill in each of the distinct study periods, were excluded from the study.

From a sample of more than 4 million Medicare beneficiaries, 322,396 diabetes patients, 1,198,585 hypertension patients, and 734,632 high blood cholesterol patients were identified as meeting the study requirements between October and December 2010. Table 1 presents the sample selection methodology for the study, which resulted in final analytical samples of data for 150,389 patients with diabetes, 615,618 with hypertension, and 358,795 with high blood cholesterol.

\section{Research Design}

We conducted a retrospective claims analysis from October 1, 2010, until December 31, 2012, which was divided into 3 distinct periods: index, baseline, and analysis (Figure 1). The index period was used to identify Medicare beneficiaries to be included in the study. As previous adherence could be indicative of a health conscious personality and a measure of better health-seeking tendency, a patient's prior adherence in the same therapeutic class was used as a proxy control for selfselection bias from PAB effect in the multivariate model..$^{30}$ Prior adherence was based on the patient's proportion of days covered (PDC) in the year 2011, considered the baseline period. The analysis period for this study was from January 1, 2012, to December 31, 2012.

Under provisions of the Health Insurance Portability and Accountability Act of 1996, all data specific to individual

\section{TABLE 1 Sample Selection Methodology}

\begin{tabular}{|c|c|c|c|}
\hline & $\begin{array}{c}\text { Diabetes } \\
\text { n (\%) }\end{array}$ & $\begin{array}{c}\text { Hypertension } \\
\mathrm{n}(\%)\end{array}$ & $\begin{array}{c}\text { High Blood } \\
\text { Cholesterol } \\
\text { n (\%) }\end{array}$ \\
\hline $\begin{array}{l}\text { Total Medicare patients in } \\
\text { the study period }\end{array}$ & 322,396 & $1,198,585$ & 734,632 \\
\hline Patients aged $\geq 65$ years & $\begin{array}{c}259,479 \\
(80.5) \\
\end{array}$ & $\begin{array}{c}1,013,617 \\
(84.6)\end{array}$ & $\begin{array}{c}621,718 \\
(84.6) \\
\end{array}$ \\
\hline $\begin{array}{l}\text { Patients continuously } \\
\text { enrolled for the entire } \\
\text { study period }\end{array}$ & $\begin{array}{c}183,770 \\
(70.8)\end{array}$ & $\begin{array}{c}717,103 \\
(70.7)\end{array}$ & $\begin{array}{c}440,047 \\
(70.8)\end{array}$ \\
\hline $\begin{array}{l}\text { Patients with at least } 1 \\
\text { claim in all periods of the } \\
\text { study timeline }\end{array}$ & $\begin{array}{l}164,385 \\
(89.5)\end{array}$ & $\begin{array}{c}677,163 \\
(94.4)\end{array}$ & $\begin{array}{c}394,813 \\
(89.7)\end{array}$ \\
\hline $\begin{array}{l}\text { Patients with claims for } \\
\text { GPI8s listed in Appendix }\end{array}$ & $\begin{array}{c}162,943 \\
(99.1) \\
\end{array}$ & $\begin{array}{c}669,957 \\
(98.9) \\
\end{array}$ & $\begin{array}{c}389,944 \\
(98.8) \\
\end{array}$ \\
\hline $\begin{array}{l}\text { Patients with no home } \\
\text { delivery auto refill } \\
\text { claims in } 2012\end{array}$ & $\begin{array}{c}150,493 \\
(92.4)\end{array}$ & $\begin{array}{c}616,821 \\
(92.1)\end{array}$ & $\begin{array}{c}359,313 \\
(92.1)\end{array}$ \\
\hline $\begin{array}{l}\text { Patients with no missing } \\
\text { values for key covariates }\end{array}$ & $\begin{array}{c}150,389 \\
(100.0) \\
\end{array}$ & $\begin{array}{c}615,618 \\
(99.8)\end{array}$ & $\begin{array}{c}358,795 \\
(99.9) \\
\end{array}$ \\
\hline
\end{tabular}

aTable shows percentage retained from each criterion to the next; percentages are rounded to 1 decimal point.

GPI8=8-digit Generic Product Identifier.

patients were removed from internal analytical datasets to maintain the privacy of protected health information. ${ }^{31}$ The design of this study was not submitted to an institutional review board, as only de-identified administrative data were used. ${ }^{22,32}$ All prescription claims were adjusted to 30-day equivalents by dividing the total dispensed days supply by 30.4 .

\section{Study Variables}

The primary outcome measure was patient adherence to diabetes, hypertension, or high blood cholesterol medications, defined as a PDC of $80 \%$ or greater in the analysis period. ${ }^{33,34}$ Patients' PDC was calculated as the total days supply divided by 365 and multiplied by 100 , capping it at 100\%. Patient-level PDC in this study is different from CMS-defined PDC at the Medicare contract level. At the drug-group level, the combination of 8-digit Generic Product Identifier (GPI) codes and clinically appropriate drug groups was used to calculate the PDC, which then was averaged to the therapy class level for each patient (see the Appendix). Drug groups were based on a proprietary method of classifying medications into clinically accepted drug subclasses within each therapy class and maintained by a panel of clinical

\section{FIGURE 1 Schematic of Study Timeline}

\begin{tabular}{|l|l|lr|}
\multicolumn{1}{|c|}{ Index Period } & \multicolumn{2}{c}{ Analysis Period } \\
\hline October 1, 2010 & January 1, 2011 & January 1, 2012 & December 31, 2012
\end{tabular}


TABLE 2 Baseline Characteristics Across Channels ${ }^{a}$

\begin{tabular}{|c|c|c|c|c|c|c|}
\hline & \multicolumn{2}{|c|}{ Home Delivery } & \multicolumn{2}{|c|}{ Retail } & \multicolumn{2}{|c|}{ Mixed } \\
\hline Diabetes $(\mathrm{N})$ & \multicolumn{2}{|c|}{20,432} & \multicolumn{2}{|c|}{127,727} & \multicolumn{2}{|c|}{2,334} \\
\hline & \multicolumn{6}{|c|}{ Mean (SD) } \\
\hline Age & 74.0 & $(6.5)^{\mathrm{b}}$ & 74.0 & $(6.5)^{c}$ & 73.8 & $(6.4)^{\mathrm{b}}$ \\
\hline OOP costs per 30-day adjusted prescriptions (\$) & 12.32 & $(16.60)$ & 7.22 & $(14.07)$ & 14.47 & $(16.27)$ \\
\hline Disease burden proxy & 4.10 & $(3.15)$ & 6.89 & $(5.00)$ & 4.79 & $(3.94)$ \\
\hline Severity of illness proxy & 1.57 & $(0.72)$ & 1.54 & $(0.70)$ & 1.93 & $(0.77)$ \\
\hline \multirow[t]{2}{*}{ Average days supply per claim } & 86.23 & $(9.37)$ & 47.08 & $(24.62)$ & 72.31 & $(19.77)$ \\
\hline & \multicolumn{6}{|c|}{ n (\%) } \\
\hline Baseline adherent beneficiaries & 14,589 & $(71.4)$ & 72,075 & $(56.4)^{\mathrm{c}}$ & 1,291 & $(55.3)^{\mathrm{c}}$ \\
\hline Female & 9,806 & $(48.0)$ & 75,041 & $(58.8)$ & 1,252 & $(53.6)$ \\
\hline Urbanicity & 19,320 & $(94.6)$ & 121,192 & $(94.9)^{\mathrm{c}}$ & 2,233 & $(95.7)^{\mathrm{c}}$ \\
\hline LIS beneficiaries & 730 & (3.6) & 37,139 & $(29.1)$ & 144 & $(6.2)$ \\
\hline \multirow[t]{2}{*}{ Hypertension $(\mathrm{N})$} & \multicolumn{2}{|c|}{105,984} & \multicolumn{2}{|c|}{496,501} & \multicolumn{2}{|c|}{14,336} \\
\hline & \multicolumn{6}{|c|}{ Mean (SD) } \\
\hline Age & 75.0 & $(7.0)$ & 75.5 & $(7.3)$ & 75.9 & $(7.1)$ \\
\hline OOP costs per 30-day adjusted prescriptions (\$) & 8.90 & $(9.99)$ & 5.97 & $(8.33)$ & 8.95 & $(8.65)$ \\
\hline Disease burden proxy & 2.01 & $(2.72)$ & 4.20 & $(4.45)$ & 2.63 & $(3.47)$ \\
\hline Severity of illness proxy & 2.01 & $(0.91)$ & 2.07 & $(0.93)$ & 2.36 & $(0.85)$ \\
\hline \multirow[t]{2}{*}{ Average days supply per claim } & 85.95 & $(8.72)$ & 50.43 & $(25.31)$ & 70.26 & $(19.18)$ \\
\hline & \multicolumn{6}{|c|}{ n (\%) } \\
\hline Baseline adherent beneficiaries & 79,328 & $(74.8)$ & 290,196 & $(58.4)$ & 8,575 & $(59.8)$ \\
\hline Female & 59,999 & $(56.6)$ & 315,389 & $(63.5)$ & 8,655 & $(60.4)$ \\
\hline Urbanicity & 100,788 & $(95.1)$ & 469,775 & $(94.6)$ & 13,772 & $(96.1)$ \\
\hline LIS beneficiaries & 2,151 & $(2.0)$ & 116,744 & $(23.5)$ & 562 & $(3.9)$ \\
\hline \multirow[t]{2}{*}{ High blood cholesterol (N) } & \multicolumn{2}{|c|}{76,420} & \multicolumn{2}{|c|}{278,777} & \multicolumn{2}{|c|}{4,116} \\
\hline & \multicolumn{6}{|c|}{ Mean (SD) } \\
\hline Age & 74.4 & $(6.6)$ & 74.6 & $(6.8)$ & 74.9 & $(6.9)$ \\
\hline OOP costs per 30-day adjusted prescriptions (\$) & 12.28 & $(15.25)$ & 7.88 & $(13.17)$ & 12.19 & $(14.93)$ \\
\hline Disease burden proxy & 3.14 & $(2.97)$ & 5.71 & $(4.71)$ & 4.54 & $(4.03)$ \\
\hline \multirow[t]{2}{*}{ Average days supply per claim } & 87.93 & $(6.91)$ & 52.89 & $(27.46)$ & 74.36 & $(20.41)$ \\
\hline & \multicolumn{6}{|c|}{$\mathrm{n}(\%)$} \\
\hline Baseline adherent beneficiaries & 63,750 & $(83.4)$ & 193,079 & $(69.3)$ & 3,049 & $(74.1)$ \\
\hline Female & 39,870 & $(52.2)$ & 169,411 & $(60.8)$ & 2,413 & $(58.6)$ \\
\hline Urbanicity & 72,816 & $(95.3)$ & 264,067 & $(94.7)$ & 3,958 & $(96.2)$ \\
\hline LIS beneficiaries & 1,405 & (1.8) & 66,973 & $(24.0)$ & 253 & (6.1) \\
\hline \multicolumn{7}{|c|}{$\begin{array}{l}\text { aAll data were significantly different at } P<0.05 \text { from both other groups, except for cells marked with a not } \\
\text { count of } 2 \text {-digit GPIs used by the patient. Number of unique drug groups for which the patient had a presc } \\
\text { hypertension. } \\
\text { bNot significantly different from the other dispensing channels at } P<0.05 \text {. } \\
\text { cSignificantly different at } P<0.05 \text { from home delivery only. } \\
\text { GPI = Generic Product Identifier; LIS =low-income subsidy; OOP=out-of-pocket; SD= standard deviation. }\end{array}$} \\
\hline
\end{tabular}

experts. Only the numbers of medication units actually meant to be taken during the study periods were included in calculations. That is, the parts of any claim that were in possession before the key periods (2011 for baseline and 2012 for analysis) and any excess in possession after the end of the periods were excluded from the adherence calculations.

In addition to dispensing channel, other patient characteristics included in this study as independent variables were age, gender, patient out-of-pocket (OOP) costs for 30-day adjusted prescriptions, location (urbanicity) of the patient, low-income subsidy (LIS) status, average days supply per claim, prior adherence, disease burden, and severity of illness. Channel determination was based on where the patient obtained at least two-thirds $(66.7 \%)$ of their therapeutic class-specific 30-day adjusted prescriptions in the year 2012. Those who did not receive at least $66.7 \%$ of their 30 -day adjusted prescriptions from either home delivery or retail were assigned to a mixed channel group. Age was calculated as the age of the patient on December 31, 2010. OOP costs for 30-day adjusted prescriptions were calculated by dividing total OOP pharmacy costs (for each therapeutic class) in 2012 by the patient's total number of 30-day adjusted prescriptions. The location vari- 
Association Between Dispensing Channel and Medication Adherence Among Medicare Beneficiaries Taking Medications to Treat Diabetes, High Blood Pressure, or High Blood Cholesterol

TABLE 3 Unadjusted Percentage Adherent by Therapy Class and Channel

\begin{tabular}{|c|c|c|c|c|c|c|c|c|c|c|c|}
\hline \multirow[b]{2}{*}{ Therapy Class ${ }^{a}$} & \multicolumn{3}{|c|}{ Home Delivery } & \multicolumn{3}{|c|}{ Retail } & \multicolumn{3}{|c|}{ Mixed } & \multirow{2}{*}{$\begin{array}{c}\text { Difference } \\
\text { Between Home } \\
\text { Delivery and } \\
\text { Retail }\end{array}$} & \multirow{2}{*}{$\begin{array}{c}\text { Difference } \\
\text { Between Home } \\
\text { Delivery and } \\
\text { Mixed }\end{array}$} \\
\hline & Total & $\begin{array}{l}\text { Number } \\
\text { Adherent }\end{array}$ & $\%$ & Total & $\begin{array}{l}\text { Number } \\
\text { Adherent }\end{array}$ & $\%$ & Total & $\begin{array}{l}\text { Number } \\
\text { Adherent }\end{array}$ & $\%$ & & \\
\hline Diabetes & 20,432 & 13,669 & 66.9 & 127,727 & 67,951 & 53.2 & 2,334 & 1,106 & 47.4 & 13.7 & 19.5 \\
\hline Hypertension & 105,984 & 77,050 & 72.7 & 496,501 & 281,020 & 56.6 & 14,336 & 7,311 & 51.0 & 16.1 & 21.7 \\
\hline High blood cholesterol & 76,420 & 60,448 & 79.1 & 278,777 & 181,763 & 65.2 & 4,116 & 2,527 & 61.4 & 13.9 & 17.7 \\
\hline \multicolumn{10}{|c|}{ Mean Difference } & 14.6 & 19.6 \\
\hline
\end{tabular}

able of urbanicity was based on the "core-based statistical area" used by the U.S. Census Bureau to ascertain the urban core of metropolitan and micropolitan statistical areas. ${ }^{35}$

As a proxy for socioeconomic status, LIS status was controlled for in the model. LIS (also called "Extra Help") is provided to low-income Medicare beneficiaries to provide assistance with the cost of drug coverage. Inclusion was limited to patients who remained exclusively on 1 status (either LIS or not) during the main analysis period (calendar year 2012). To address the suggestion that better adherence in home delivery is an artifact of greater days supply, average days supply per claim was used as a proxy measure to control for the differences in days supply of prescriptions between retail and home delivery channels. ${ }^{25}$

Prior adherence was included in the model to control for the PAB effect, as past behavior has been known to be a good marker for predicting future behavior. ${ }^{36} \mathrm{~A}$ similar method was used in a 2013 study examining the association of dispensing channel with medication adherence, to control for the HAE of commercially insured patients. ${ }^{27}$ Patient-level PDC was calculated for the 2010 period to establish prior adherence. In the 2013 study, patients with medication possession ratio $\geq 0.8$ during 2010 were classified as being adherent in the prior period, in the aforementioned study.

In addition to sociodemographic variables in this study, proxy covariates to control for patient disease burden and severity of illness were included. Patients' overall disease burden was defined as the number of unique 2-digit GPIs, indicating drug therapy classes used by the patient. Number of unique drug groups for which the patient had a prescription claim in 2012 defined the severity of illness for diabetes and hypertension. For high blood cholesterol, only adherence to statins was analyzed, and thus high blood cholesterol had only 1 drug group. As disease burden and severity of illness are proxy measures derived from claims, these are referred to together as drug-use pattern. Percentage adherent for each condition was defined as the percentage of patients in each cohort (home delivery/retail/mixed) who had a PDC of $80 \%$ or greater.

\section{Analysis}

Descriptive statistics were estimated; bivariate differences between groups were tested using Kruskal-Wallis (nonparametric) tests for all continuous variables; and chi-square tests were performed for categorical variables. Multivariate logistic regression analyses were performed to estimate the association of covariates with the odds of being adherent.

Additionally, an analysis on a subsample of patients filling exclusively 90-day prescriptions evaluated the impact of channel on adherence. Inclusion was limited to patients who filled all their prescriptions through 1 channel only (either retail or home delivery). The final analytical subanalysis sample comprised data for 28,116 patients with diabetes, 123,020 with hypertension, and 120,478 with high blood cholesterol. All analyses were conducted using SAS version 9.3 (SAS Institute, Cary, NC).

\section{Results}

\section{Descriptive Findings}

Patients using home delivery tended to be similar in age to those using retail but included a lower proportion of females than retail or mixed channels (Table 2). Home delivery patients had higher average days supply per claim, lower average disease burden, and similar mean severity of illness (for diabetes and hypertension) compared with retail patients. However, patients in the mixed group had a greater severity of illness compared with home delivery or retail patients. Home delivery patients also had slightly higher OOP costs per 30-day adjusted prescriptions than retail, an artifact of drug mix and differences in proportion of beneficiaries with LIS. Proportion of patients on LIS status was significantly lower for home delivery compared with retail and mixed group. Across all 3 classes, prior adherence was significantly higher in home delivery than in retail or mixed channels, reflecting the importance of using a proxy measure to control for PAB in the model in order to obtain less biased estimates of the effect of dispensing channel on adherence.

On average, home delivery had $14.6 \%$ more adherent patients than retail and $19.6 \%$ more than mixed channels across the 3 therapy classes. Unadjusted adherence rates for those using home delivery were consistently higher than for patients using retail, with percentage point differences ranging from $13.7 \%$ for antidiabetics to $16.1 \%$ for antihypertensives (Table 3). 
TABLE 4 Odds Ratio of Adherence by Therapy Class ${ }^{a}$

\begin{tabular}{|c|c|c|c|c|}
\hline & $\mathrm{OR}^{\mathrm{b}}$ & $95 \% \mathrm{CI}$ & $\mathrm{OR}^{\mathrm{b}}$ & $95 \% \mathrm{CI}$ \\
\hline Diabetes & \multicolumn{2}{|c|}{ Model $1(n=150,389)$} & \multicolumn{2}{|c|}{ Model $2(n=28,116)$} \\
\hline Home delivery vs. retail & 1.252 & $1.204-1.303$ & 1.393 & $1.314-1.477$ \\
\hline Mixed vs. retail & $0.874^{c}$ & $0.797-0.958$ & NA & NA \\
\hline Age & 0.991 & $0.989-0.993$ & 0.990 & $0.986-0.994$ \\
\hline Female vs. male & 0.951 & $0.930-0.974$ & 0.911 & $0.862-0.962$ \\
\hline OOP costs 30-day adjusted & 0.997 & $0.996-0.998$ & 0.996 & $0.994-0.998$ \\
\hline Disease burden & 1.005 & $1.003-1.008$ & $1.000^{\mathrm{d}}$ & $0.993-1.008$ \\
\hline Severity of illness & 0.533 & $0.524-0.542$ & 0.624 & $0.597-0.653$ \\
\hline Urbanicity & $0.981^{\mathrm{d}}$ & $0.933-1.033$ & $0.923^{\mathrm{d}}$ & $0.819-1.041$ \\
\hline Average days supply per claim & 1.007 & $1.007-1.008$ & NA & NA \\
\hline LIS & 1.120 & $1.090-1.152$ & $1.042 \mathrm{~d}$ & $0.946-1.147$ \\
\hline Prior adherence & 4.657 & $4.552-4.765$ & 4.830 & $4.558-5.119$ \\
\hline Hypertension & \multicolumn{2}{|c|}{ Model $1(n=615,618)$} & \multicolumn{2}{|c|}{ Model $2(n=123,020)$} \\
\hline Home delivery vs. retail & 1.294 & $1.271-1.318$ & 1.588 & $1.540-1.638$ \\
\hline Mixed vs. retail & 0.744 & $0.717-0.772$ & NA & NA \\
\hline Age & 0.991 & $0.990-0.992$ & 0.988 & $0.986-0.990$ \\
\hline Female vs. male & 1.060 & $1.047-1.072$ & 1.067 & $1.037-1.099$ \\
\hline OOP costs 30-day adjusted & 0.999 & 0.998-0.999 & $1.002^{\mathrm{e}}$ & $1.000-1.004$ \\
\hline Disease burden & 1.012 & $1.011-1.014$ & 1.016 & $1.011-1.022$ \\
\hline Severity of illness & 0.649 & $0.645-0.653$ & 0.811 & $0.797-0.825$ \\
\hline Urbanicity & $0.959^{c}$ & $0.935-0.983$ & $0.906^{c}$ & $0.850-0.966$ \\
\hline Average days supply per claim & 1.009 & $1.009-1.009$ & NA & NA \\
\hline LIS & 1.132 & $1.114-1.149$ & 1.122 & $1.055-1.193$ \\
\hline Prior adherence & 4.477 & $4.426-4.529$ & 6.452 & $6.258-6.652$ \\
\hline High blood cholesterol & \multicolumn{2}{|c|}{ Model $1(n=358,795)$} & \multicolumn{2}{|c|}{ Model $2(n=120,478)$} \\
\hline Home delivery vs. retail & 1.256 & $1.226-1.287$ & 1.261 & $1.223-1.301$ \\
\hline Mixed vs. retail & 0.628 & $0.585-0.675$ & NA & NA \\
\hline Age & 0.991 & $0.990-0.992$ & 0.986 & $0.984-0.989$ \\
\hline Female vs. male & 0.919 & $0.904-0.934$ & 0.924 & $0.897-0.952$ \\
\hline OOP costs 30-day adjusted & 0.995 & $0.995-0.996$ & 0.994 & $0.993-0.995$ \\
\hline Disease burden & $1.003^{\mathrm{c}}$ & $1.001-1.004$ & 1.011 & $1.007-1.016$ \\
\hline Severity of illness & NA & NA & NA & NA \\
\hline Urbanicity & $0.981^{\mathrm{d}}$ & $0.946-1.018$ & $1.032^{\mathrm{d}}$ & $0.967-1.101$ \\
\hline Average days supply per claim & 1.008 & $1.007-1.008$ & $\mathrm{NA}$ & NA \\
\hline LIS & 1.075 & $1.052-1.098$ & $1.004 \mathrm{~d}$ & $0.945-1.067$ \\
\hline Prior adherence & 8.091 & $7.956-8.227$ & 7.219 & $6.990-7.457$ \\
\hline \multicolumn{5}{|c|}{ 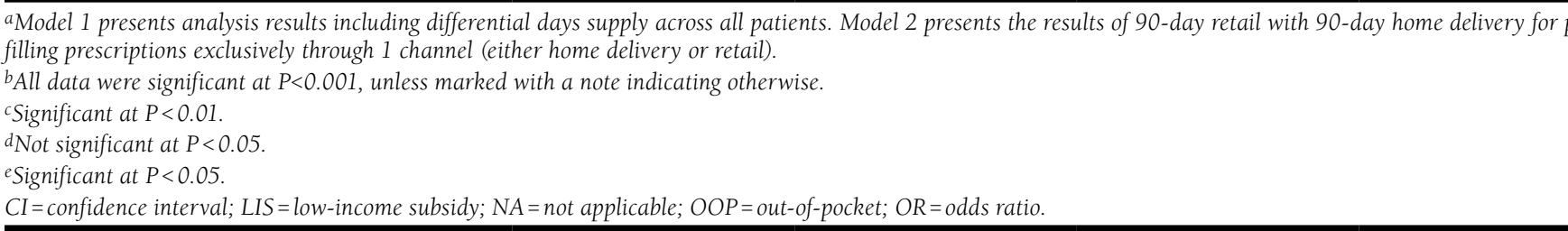 } \\
\hline
\end{tabular}

The results of a direct comparison for a subset of patients filling 90-day prescriptions in retail with patients filling 90-day prescriptions in home delivery also indicated that adherence rates were significantly higher in home delivery compared with retail for diabetes $(72.0 \%$ vs. $66.1 \%, P<0.001)$, hypertension $(81.4 \%$ vs. $72.0 \%, P<0.001)$, and high blood cholesterol (79.3\% vs. $74.9 \%, P<0.001)$. The 90 -day analysis was based on a sample of 28,116 people with diabetes, 123,020 with hypertension, and 120,478 with high blood cholesterol.

\section{Multivariate Findings}

The results presented in Table 4 indicate the significance of controlling for the PAB effect and the impact of the channel classification criterion and differential days supply. The results also offer insights into a more direct comparison between 90-day retail and 90-day home delivery, although only a small portion of beneficiaries received 90-day supplies through retail. Model 1 presents the odds of a patient (including all days 
Association Between Dispensing Channel and Medication Adherence Among Medicare Beneficiaries Taking Medications to Treat Diabetes, High Blood Pressure, or High Blood Cholesterol

TABLE 5 Adjusted Percentage Adherent by Therapy Class and Channel

\begin{tabular}{|c|c|c|c|c|c|c|c|c|c|c|c|}
\hline \multirow[b]{2}{*}{ Therapy Class ${ }^{\mathrm{a}}$} & \multicolumn{3}{|c|}{ Home Delivery } & \multicolumn{3}{|c|}{ Retail } & \multicolumn{3}{|c|}{ Mixed } & \multirow{2}{*}{$\begin{array}{c}\text { Difference } \\
\text { Between Home } \\
\text { Delivery and } \\
\text { Retail }\end{array}$} & \multirow{2}{*}{$\begin{array}{c}\text { Difference } \\
\text { Between Home } \\
\text { Delivery and } \\
\text { Mixed }\end{array}$} \\
\hline & Total & $\begin{array}{l}\text { Number } \\
\text { Adherent }\end{array}$ & $\%$ & Total & $\begin{array}{l}\text { Number } \\
\text { Adherent }\end{array}$ & $\%$ & Total & $\begin{array}{l}\text { Number } \\
\text { Adherent }\end{array}$ & $\%$ & & \\
\hline Diabetes & 20,410 & 12,328 & 60.4 & 127,648 & 70,079 & 54.9 & 2,331 & 1,203 & 51.6 & 5.5 & 8.8 \\
\hline Hypertension & 105,860 & 69,868 & 66.0 & 495,459 & 297,275 & 60.0 & 14,299 & 7,536 & 52.7 & 6.0 & 13.3 \\
\hline High blood cholesterol & 76,302 & 56,998 & 74.7 & 278,389 & 195,151 & 70.1 & 4,104 & 2,446 & 59.6 & 4.5 & 15.1 \\
\hline & & & & & & & & Mean Dif & erence & 5.3 & 12.4 \\
\hline
\end{tabular}

Therapy class totals: diabetes-150,389; hypertension-615,618; high blood cholesterol-358,795.

supply and any dispensing channel) being adherent, controlling for PAB. Results of channel-adherence relationship for 90-day home delivery versus 90-day retail, controlling for the PAB effect, are presented in Model 2. PAB had a significant impact on the results, as observed from the corresponding odds ratio. It was the strongest contributor to the odds of a patient being adherent across all 3 therapy classes. Odds ratios ranged from 4.48 to 8.09 , indicating that adherent beneficiaries in the baseline period were 4 to 8 times more likely to be adherent in the main analysis period, irrespective of the channel from which they filled their medications.

After controlling for relevant population differences (age, gender, and patient OOP costs per 30-day adjusted prescriptions) and key covariates (PAB, average days supply per claim, disease burden, severity of illness, and urbanicity), the differences in adherence between the dispensing channels is significant (Table 4, Model 1). In 2012, the odds of a home delivery patient being adherent were approximately 1.25 times higher than that of a retail patient for diabetes medications, 1.29 times higher for hypertension medications, and 1.26 times higher for high blood cholesterol medications. The odds of being adherent for a patient using mixed channels were approximately 13\% to $37 \%$ lower than the odds of a retail patient for antidiabetics, antihypertensives, and antihyperlipidemics.

Isolating the effect size of dispensing channel on medication adherence, based on the multivariate model presented in Table 4, Model 1, we found that on average, home delivery had 5.3\% more adherent patients than retail and $12.4 \%$ more than those using mixed channels across the 3 therapy classes (Table 5). Adjusted adherence rates for those using home delivery were consistently higher than for patients using retail, with percentage point differences ranging from $4.5 \%$ for antihyperlipidemics to $6.0 \%$ for antihypertensives. Adjusted adherence rate for antidiabetics was 5.5\% higher for patients using the home delivery channel compared with retail.

Additional sensitivity analysis, examining patients filling only 90-day prescriptions (Table 4, Model 2), concluded that the adjusted odds of being adherent were significantly higher in home delivery compared with retail. For diabetes patients, odds ratio $[\mathrm{OR}]=1.39$ (95\% confidence interval $[\mathrm{CI}]=1.31$ 1.48), for hypertension patients $\mathrm{OR}=1.59(\mathrm{CI}=1.54-1.64)$, and for high blood cholesterol patients $\mathrm{OR}=1.26(\mathrm{CI}=1.22-1.30)$. These data indicate that home delivery patients using antidiabetics were 39\% more likely, patients using antihypertensives were 59\% more likely, and patients using antihyperlipidemics were $26 \%$ more likely to be adherent than their respective retail counterparts, even after equalizing the days supply differences.

\section{Discussion}

Medicare beneficiaries using home delivery were significantly more adherent compared with their retail counterparts, after controlling for demographics, drug-use patterns, differences in days supply, and the PAB effect. The findings from the main model, as well as the model comparing 90-day retail to 90-day home delivery users, were consistent across the 3 studied therapy classes. For all 3 of the conditions, patients classified as using a mixed channel had significantly lower adherence rates compared with patients who received $66.7 \%$ or more of their prescriptions from either retail or home delivery. Controlling for the PAB effect, adjusting for the difference in days supply in all models, and including only those patients who did not participate in a home delivery auto refill program, the results offer empirical evidence that home delivery leads to greater odds of being adherent in Medicare patients. The multivariate adjusted coefficients on OOP costs, disease burden, and severity of illness are consistent with previous research. ${ }^{27}$ Estimates of adherence behavior with respect to dispensing channel are less likely to be biased than previous Medicare channel-adherence studies, since this study used prior adherence to identify and control for the PAB effect.

This study makes an important contribution in the area of healthy adherer impact by controlling for the PAB effect, which few studies have addressed. ${ }^{27,30}$ A study by Iyengar et al. (2013) examined the association between dispensing channel and medication adherence, using PAB as a proxy control for healthy adherer effect. ${ }^{27}$ However, that study was conducted on a commercially insured population aged 64 years or younger and did not exclude patients receiving prescriptions via home delivery 
auto refill programs. Patrick et al.'s (2011) study on statins used prior adherence to identify healthy adherers in the context of outcomes but did not examine the association with dispensing channel. ${ }^{30}$ Our study builds on the methods of the previous studies and applies it to the Medicare population. Researchers have stressed the need to address the confounding impact of patients' predisposition to be adherent while examining any adherence-related relationship..$^{28,29,37}$ To our knowledge, this research is the first to address this concern among Medicare beneficiaries.

Apart from the clinical benefits of better adherence in terms of improved health outcomes, the findings of this study have important financial implications for Medicare Advantage health plans. Better adherence may improve a Medicare health plan's Five-Star rating, which could result in greater reimbursement from Medicare.

Additionally, various factors such as inability to visit a pharmacy, daily schedule, forgetfulness, or procrastination can result in failure to obtain medications in time among many patients who intend to take their medications as prescribed. Home delivery pharmacies offer convenience to patients and are an effective alternative to retail pharmacies for continued access to medications. ${ }^{22}$ Access issues and financial difficulties are also 2 factors identified as detrimental to adherence. ${ }^{38-40}$ As prescriptions are delivered to patients' homes, and as the total patient OOP costs are frequently less in home delivery pharmacies, the impact of these 2 concerns are eased for many patients. This could potentially be driving the higher adherence rates as well as higher likelihood of being adherent among Medicare members using home delivery.

\section{Limitations}

There are several limitations to this study, most of which result from only having access to pharmacy claims data. The findings from this study should be interpreted in view of the following limitations.

Because the study sample was limited to Medicare Part D (MAPD and PDP) patients aged 65 years and above, the results of the analyses may not be generalizable to other populations, such as dual eligible or Employer Group Waiver Plan beneficiaries.

This study used PDC as a proxy for medication-taking behavior, which assumes that a pill in hand is a pill taken, which may not always be true. However, the use of pharmacy claims to ascertain adherence to medication use has been well documented in previous studies. ${ }^{22,30,33}$ Further, claims data cannot help distinguish between nonadherence and prescriber recommended discontinuation.

Our study design included patients on medication for at least 2 years. Thus, patients who did not fill at least 1 prescription in each of the distinct time periods of the study were excluded from the analysis. However, since diabetes, hypertension, and high blood cholesterol medications typically need to be used continually in the Medicare population, one would expect the impact of this limitation to be minimal.

Our results do not account for the differential impact of the coverage gap on medication adherence. Beneficiaries who were adherent to their medications prior to reaching the coverage gap might become nonadherent after reaching the gap.

We could not identify patients engaged in retail auto refill programs, so our estimates of retail adherence might be inflated and our study conclusions conservative.

We did not control for the impact of medication therapy management (MTM) programs on adherence. As MTM programs are available for all Medicare plans and are delivered either face-to-face or telephonically, this availability should not differentially bias patients using home delivery or retail. However, face-to-face MTM may be lower if all medications are delivered to the patient's home.

This study also did not control for other confounders such as education and income that could impact adherence. However, inclusion of LIS status as a proxy for socioeconomic status should minimize the potential bias resulting from this limitation.

Our results are as robust as the reliability and validity of the proxy measures that were used to control for the confounding effects of covariates in the relationship between dispensing channel and adherence. This study had access only to pharmaceutical claims data, and lack of medical information and patient self-reported data is a limitation of this study. Further studies should incorporate medical and patient self-reported data to strengthen and validate the proxy variables.

Our study evaluated the impact of the dispensing channel on adherence to medications in 3 widely used chronic therapy classes. Future research could use a similar approach to expand the analysis across additional maintenance therapy classes, such as ischemic heart disease, chronic obstructive pulmonary disease, and arthritis, which are also prevalent and expensive conditions among Medicare beneficiaries.

Our study indicates low therapy class-specific adherence rates. Our data had a high proportion of patients (about 65\%) on LIS status, which is a proxy for poor socioeconomic status. Literature suggests that financial concerns are detrimental to medication adherence. ${ }^{39,40}$ We may thus be observing poor rates of adherence among our patient population. However, our study statistically controlled for LIS status in the multivariate model. Hence, the potential for bias would be reduced.

The results from this analysis suggest medication adherence varies by therapy class. Patients' overall medication adherence could vary depending on their comorbid conditions (e.g., diabetes and hypertension, hypertension and high blood cholesterol, or diabetes and high blood cholesterol). This analysis looked at a patient's medication adherence in each therapy class independently. Additional studies could examine the variation in the impact of dispensing channel on medication adherence among patients with different combinations of comorbid conditions. 


\section{Association Between Dispensing Channel and Medication Adherence Among Medicare Beneficiaries Taking Medications to Treat Diabetes, High Blood Pressure, or High Blood Cholesterol}

\section{Conclusions}

We found that patients receiving their medications via home delivery had greater adherence than those receiving their medications from retail pharmacies, even after accounting for differences in days supply and LIS status. By excluding beneficiaries who obtained their prescriptions via home delivery auto refill programs, this study provides support that home delivery signifies an important alternative that is associated with better adherence rates. Both the main model and the 90-day comparison indicate that home delivery channel is associated with improved adherence rates and that this improvement is not simply a by-product of self-selection, increased days supply, LIS status, or home delivery auto refill programs.

Our study presents home delivery as a viable complementary strategy to address medication nonadherence and provides evidence to CMS, health plan sponsors, and managed care organizations, encouraging use of more effective dispensing channels.

\section{Authors}

REETHI N. IYENGAR, PhD, MBA, MHM, is Senior Manager, Health Services Research; DHANUR S. BALAGERE, MS, is Senior Manager, Outcomes Research; ROCHELLE R. HENDERSON, PhD, MPA, is Director, Health Services Research; ABBEY L. LEFRANCOIS, PharmD, is Director, Clinical Program Management, Government Programs; REBECCA M. RABBITT, MS, PharmD, is Senior Director, Product Management, Medicare; and SHARON GLAVE FRAZEE, PhD, MPH, is Vice President, Research and Analytics, Express Scripts Holding Company, St. Louis, Missouri.

AUTHOR CORRESPONDENCE: Reethi N. Iyengar, PhD, MBA, MHM, Health Services Research, Express Scripts, 4600 N. Hanley Rd., PTIC08, St. Louis, MO 63134. E-mail: rniyengar@express-scripts.com.

\section{DISCLOSURES}

The authors and contributors are employees of Express Scripts Holding Company, which provided funding for this study.

Concept and design were contributed by Iyengar and Balagere, who were also primarily responsible for data collection, with assistance from other the authors. Statistical analysis was performed by Iyengar and Balagere, with data interpretation by LeFrancois, Frazee, and Iyengar, aided by the other authors. The manuscript was written chiefly by lyengar and Henderson, and all authors participated in revision.

\section{ACKNOWLEDGMENTS}

The authors thank Mark Eatherly, BS; Seth Goldfarb, MS; Ryan Stoll, MBA; Don Belfer, BS; Joel Basinger, BS; and Audra Nawrocki, MBA, for their assistance with data management and valuable data insights. Ruth Martinez, RPh, also deserves thanks for her helpful suggestions in the review of the manuscript. In addition, the authors wish to thank the reviewers. Their insightful suggestions helped to improve this article.

\section{REFERENCES}

1. Centers for Medicare \& Medicaid Services. Chronic conditions among Medicare beneficiaries. Chartbook: 2012 ed. Available at: http://www.cms gov/Research-Statistics-Data-and-Systems/Statistics-Trends-and-Reports/ Chronic-Conditions/Downloads/2012Chartbook.pdf. Accessed May 21, 2014

2. Osterberg L, Blaschke T. Adherence to medication. N Engl J Med. 2005;353(5):487-97.

3. Brunton SA. Improving medication adherence in chronic disease management. J Fam Pract. 2011;60(4 Suppl):S1-S8.

4. Blanchard J, Madden JM, Ross-Degnan D, Gresenz CR, Soumerai SB The relationship between emergency department use and cost-related medication nonadherence among Medicare beneficiaries. Ann Emerg Med. 2013;62(5):475-85.

5. Stuart BC, Simoni-Wastila L, Zhao L, Lloyd JT, Doshi JA. Increased persistency in medication use by U.S. Medicare beneficiaries with diabetes is associated with lower hospitalization rates and cost savings. Diabetes Care. 2009;32(4):647-49.

6. Mojtabai R, Olfson M. Medication costs, adherence, and health outcomes among Medicare beneficiaries. Health Aff (Millwood). 2003;22(4):220-29.

7. Albert NM. Improving medication adherence in chronic cardiovascular disease. Crit Care Nurse. 2008;28(5):54-64.

8. DiMatteo MR, Giordani PJ, Lepper HS, Croghan TW. Patient adherence and medical treatment outcomes: a meta-analysis. Med Care. 2002;40(9):794-811.

9. McDermott MM, Schmitt B, Wallner E. Impact of medication nonadherence on coronary heart disease outcomes: a critical review. Arch Intern Med. 1997;157(17):1921-29.

10. New England Healthcare Institute. Thinking outside the pillbox: a system-wide approach to improving patient medication adherence for chronic disease. August 12, 2009. Available at: http://www.nehi.net/publications/17thinking-outside-the-pillbox-a-system-wide-approach-to-improving-patientmedication-adherence-for-chronic-disease/view. Accessed May 21, 2014.

11. Dall TM, Blanchard TD, Gallo PD, Semilla AP. The economic impact of Medicare Part D on congestive heart failure. Am J Manag Care. 2013; 19(6 Suppl):S97-S100

12. Stuart B, Loh FE, Roberto P, Miller LM. Increasing Medicare Part D enrollment in medication therapy management could improve health and lower costs. Health Aff (Millwood). 2013;32(7):1212-20.

13. Williams J, Steers WN, Ettner SL, Mangione CM, Duru OK. Cost-related nonadherence by medication type among Medicare Part D beneficiaries with diabetes. Med Care. 2013;51(2):193-98

14. Kennedy J, Tuleu I, Mackay K. Unfilled prescriptions of Medicare beneficiaries: prevalence, reasons, and types of medicines prescribed. J Manag Care Pharm. 2008;14(6):553-60. Available at: http://www.amcp.org/WorkArea/ DownloadAsset.aspx?id=7948.

15. Zhang Y, Baik SH, Lave JR. Effects of Medicare Part D coverage gap on medication adherence. Am J Manag Care. 2013;19(6):e214-e24.

16. Centers for Medicare $\&$ Medicaid Services. Closing the coverage gap-Medicare prescription drugs are becoming more affordable. Revised February 2014. Available at: http://www.medicare.gov/Pubs/pdf/11493.pdf. Accessed May 21, 2014.

17. Reid RO, Deb P, Howell BL, Shrank WH. Association between Medicare Advantage plan star ratings and enrollment. JAMA. 2013;309(3):267-74.

18. Zhang L, Zakharyan A, Stockl KM, Harada AS, Curtis BS, Solow BK. Mail-order pharmacy use and medication adherence among Medicare Part D beneficiaries with diabetes. J Med Econ. 2011;14(5):562-67.

19. Duru OK, Schmittdiel JA, Dyer WT, et al. Mail-order pharmacy use and adherence to diabetes-related medications. Am J Manag Care. 2010;16(1):33-40.

20. Sharma KP, Taylor TN. Pharmacy effect on adherence to antidiabetic medications. Med Care. 2012;50(8):685-91. 
21. Carroll NV, Brusilovsky I, York B, Oscar R. Comparison of costs of community and mail service pharmacy. J Am Pharm Assoc (2003). 2005;45(3):336-43

22. Visaria J, Frazee SG, Devine ST. Asthma controller adherence in mail order pharmacy compared with retail pharmacy. Am J Pharm Benefits. 2012;4(3):e73-e80.

23. Schmittdiel JA, Karter AJ, Dyer WT, Chan J, Duru OK. Safety and effectiveness of mail order pharmacy use in diabetes. Am J Manag Care. 2013;19(11):882-87.

24. Khandelwal N, Duncan I, Rubinstein E, et al. Medication adherence for 90-day quantities of medication dispensed through retail and mail order pharmacies. Am J Manag Care. 2011;17(11):e427-e34.

25. Liberman JN, Girdish C. Recent trends in the dispensing of 90-daysupply prescriptions at retail pharmacies: implications for improved convenience and access. Am Health Drug Benefits. 2011;4(2):95-100.

26. Brennan TA, Dollear TJ, Hu M, et al. An integrated pharmacy-based program improved medication prescription and adherence rates in diabetes patients. Health Aff (Millwood). 2012;31(1):120-29.

27. Iyengar R, Henderson R, Visaria J, Frazee SG. Dispensing channel and medication adherence: evidence across 3 therapy classes. Am J Manag Care. 2013;19(10):798-804.

28. Krumholz HM. Outcomes research: generating evidence for best practice and policies. Circulation. 2008;118(3):309-18.

29. Brookhart MA, Stürmer T, Glynn RJ, Rassen J, Schneeweiss S. Confounding control in healthcare database research: challenges and potential approaches. Med Care. 2010;48(6 Suppl):S114-S20.

30. Patrick AR, Shrank WH, Glynn RJ, et al. The association between statin use and outcomes potentially attributable to an unhealthy lifestyle in older adults. Value Health. 2011;14(4):513-20.
31. U.S. Department of Health and Human Services. Basic HHS policy for protection of human research subjects, 45 C.F.R. Part 46 (2009).

32. Wu EQ, Johnson S, Beaulieu N, et al. Healthcare resource utilization and costs associated with non-adherence to imatinib treatment in chronic myeloid leukemia patients. Curr Med Res Opin. 2010;26(1):61-69.

33. Yeaw J, Benner JS, Walt JG, Sian S, Smith DB. Comparing adherence and persistence across 6 chronic medication classes. J Manag Care Pharm. 2009;15(9):728-40. Available at: http://www.amcp.org/WorkArea/ DownloadAsset.aspx?id=8250.

34. Karve S, Cleves MA, Helm M, Hudson TJ, West DS, Martin BC. An empirical basis for standardizing adherence measures derived from administrative claims data among diabetic patients. Med Care. 2008;46(11):1125-33.

35. U.S. Census Bureau. Metropolitan and micropolitan statistical areas main. Revised May 6, 2013. Available at: http://www.census.gov/population/ metro/. Accessed May 21, 2014.

36. Janis IB, Nock MK. Behavioral forecasts do not improve the prediction of future behavior: a prospective study of self-injury. J Clin Psychol. 2008;64(10):1164-74

37. Brookhart MA, Patrick AR, Dormuth C, et al. Adherence to lipid lowering therapy and the use of preventive health services: an investigation of the healthy user effect. Am J Epidemiol. 2007;166(3):348-54.

38. Samaras K, Campbell LV, Chisholm DJ. Can the effectiveness of physical activity programs be improved? Response to Clark. Diabetes Care. 1998;21(1):195-96.

39. Giannetti V. Adherence to therapeutic regimens. Res Social Adm Pharm. 2005;1(3):375-77.

40. Shay LE. A concept analysis: adherence and weight loss. Nurs Forum. 2008;43(1):42-52 


\section{APPENDIX List of Drugs and Their GPI Numbers Used to Calculate PDCa}

The GPI, from Medi-Span, is a hierarchical identifier comprising 7 subsets of 2 digits each that provide progressively more detailed information about a drug, specific to treatment indication.

Diabetes

- Sulfonylureas

27-20-00-20, 27-20-00-27, 27-20-00-30, 27-20-00-40, 27-20-00-50, 27-20-00-60, 27-99-78-02

- Biguanides

27-25-00-50, 27-99-25-02, 27-99-50-02, 27-99-70-02, 27-99-80-02

- Meglitinide analogues

27-28-00-40, 27-28-00-60

- Alpha-glucosidase inhibitors 27-50-00-10, 27-50-00-50

- Dipeptidyl peptidase-4 (DPP-4) inhibitors 27-55-00-50, 27-55-00-65, 27-55-00-70, 27-99-30-02

- Insulin sensitizing agents $27-60-70-50,27-60-70-60$

Hypertension

- Diuretics

37-20-00-10, 37-20-00-20, 37-20-00-30, 37-20-00-80, 37-50-00-10, 37-50-00-20, 37-50-00-30, 37-60-00-10, 37-60-00-20, 37-60-00-25, 37-60-00-40, $37-60-00-50,37-60-00-55,37-60-00-60,37-99-00-02$

- Beta blockers

33-10-00-10, 33-10-00-25, 33-10-00-30, 33-10-00-40, 33-10-00-45, 33-10-00-50, 33-20-00-10, 33-20-00-20, 33-20-00-21, 33-20-00-22, 33-20-00-30, $33-20-00-40,33-30-00-07,33-30-00-10,36-99-20-02$

- Calcium channel blockers

34-00-00-03, 34-00-00-10, 34-00-00-13, 34-00-00-15, 34-00-00-18, 34-00-00-20, 34-00-00-24, 34-00-00-30

- Angiotensin-converting enzyme inhibitors (ACEs)/angiotensin II receptor blockers (ARBs)/direct renin inhibitors 36-10-00-05, 36-10-00-10, 36-10-00-20, 36-10-00-27, 36-10-00-30, 36-10-00-33, 36-10-00-35, 36-10-00-40, 36-10-00-50, 36-10-00-60, 36-15-00-10, 36-15-00-20, 36-15-00-24, 36-15-00-30, 36-15-00-40, 36-15-00-55, 36-15-00-70, 36-15-00-80, 36-17-00-10, 36-99-15-02, 36-99-18-02, 36-99-30-02, $36-99-40-02,36-99-45-03,36-99-60-02,36-99-67-02,36-99-68-03$

High blood cholesterol

- HMG CoA reductase inhibitors

39-40-00-10, 39-40-00-30, 39-40-00-50, 39-40-00-58, 39-40-00-60, 39-40-00-65, 39-40-00-75, 39-40-99-02, 39-99-40-02

aPowders and injectibles have been excluded from the therapeutic classes.

$G P I=$ Generic Product Identifier; $P D C=$ proportion of days covered. 